\title{
The effect of endotoxin adsorber haemoperfusion on microcirculation in septic pigs
}

\author{
Y-C Yeh ${ }^{1 *}$, C-Y Wu ${ }^{1}$, A Chao ${ }^{1}$, W-S Chan ${ }^{2}$, Y-J Cheng ${ }^{1}$, W-Z Sun ${ }^{1}$, T-Y Lin ${ }^{2}$, \\ NTUH Center of Microcirculation Medical Research (NCMMR) \\ From ESICM LIVES 2015 \\ Berlin, Germany. 3-7 October 2015
}

\section{Introduction}

Microcirculatory dysfunction plays an important role in sepsis-related multiple organ dysfunction.(1) Several studies has shown polymyxin B hemoperfusion has favorable effects on mean arterial pressure, vasopressor use, and mortality.(2) One rat sepsis study had found that microcirculation was better maintained in the polymyxin B hemoperfusion group.(3) However, the effects of polymyxin B hemoperfusion on the microcirculation of the intestinal mucosa, intestinal muscular-serosal layer, kidney, and liver were unknown. We used a fecal peritonitis-induced septic pig model to investigate the effect of polymyxin B perfusion on the microcirculation.

\section{Objectives}

This animal study aimed to investigate the effect of polymyxin B-immobilized fiber column hemoperfusion on the microcirculation of multiple organs in septic pigs.

\section{Methods}

Eighteen male Lanyu pigs (Taitung Animal Propagation Station, Taiwan, body weight $25 \pm 4 \mathrm{~kg}$ ) will be investigated. This study was approved by the Institutional Animal Care and Use Committee. The animals were randomly assigned to the following 3 groups: 1 - Sham; 2 Sepsis (fecal peritonitis model); and 3 - Sepsis + PMX-HP (fecal peritonitis model + polymyxin B-immobilized fiber column hemoperfusion). Time course of the animal model is shown in the Figure 1.

In the Sepsis and Sepsis + PNX-HP groups, $0.5 \mathrm{~g} / \mathrm{kg}$ autologous feces and $200 \mathrm{~mL} 5 \%$ glucose were injected into the abdominal cavity. The hemodynamic parameter

${ }^{1}$ National Taiwan University Hospital, Department of Anesthesiology, Taipei, Taiwan, Province of China

Full list of author information is available at the end of the article was monitored by the Pulse index Contour Continuous Cardiac Output system. A sidestream dark-field video microscope and a tissue oxygen monitor were used to investigate microcirculation.

\section{Results}

12 pigs completed the study (4 for each group). The hemodynamic parameters were shown in the Table 1.

The perfused small vessel density (PSVD) of the terminal ileal mucosa in the septic pigs was less than the non-septic pigs at $0 \mathrm{~h}\left(24.3 \mathrm{~mm} / \mathrm{mm}^{2}\right.$ vs. $30.0 \mathrm{~mm} / \mathrm{mm}^{2}$, $\mathrm{p}=0.005)$. The images of the microcirculation of the terminal ileal mucosa at $6 \mathrm{~h}$ were shown in Figure 2.

Table 2 represents that the PSVD of the terminal ileal mucosa at $6 \mathrm{~h}$ in the Sepsis + PMX-HP group had a trend to be greater than the Sepsis group $\left(25.7 \mathrm{~mm} / \mathrm{mm}^{2}\right.$ vs. $16.3 \mathrm{~mm} / \mathrm{mm}^{2}, \mathrm{p}=0.066$ ).

The images of the microcirculation of the kidney surface at $6 \mathrm{~h}$ were shown in Figure 3.

Table 3 represents the fact that the urine output in the Sepsis + PMX-HP group was greater than in the Sepsis group.

\section{Conclusions}

In summary, we found that polymyxin B hemoperfusion for septic pigs improves urine output and has a potential to attenuate the microcirculatory dysfunction of the terminal ileal mucosa.

\section{Grant Acknowledgment}

Supported, in part, by research grant 103-FTN11 and NTUH.103-A125 from the Far Eastern Memorial Hospital and National Taiwan University Hospital Joint Research Program. 


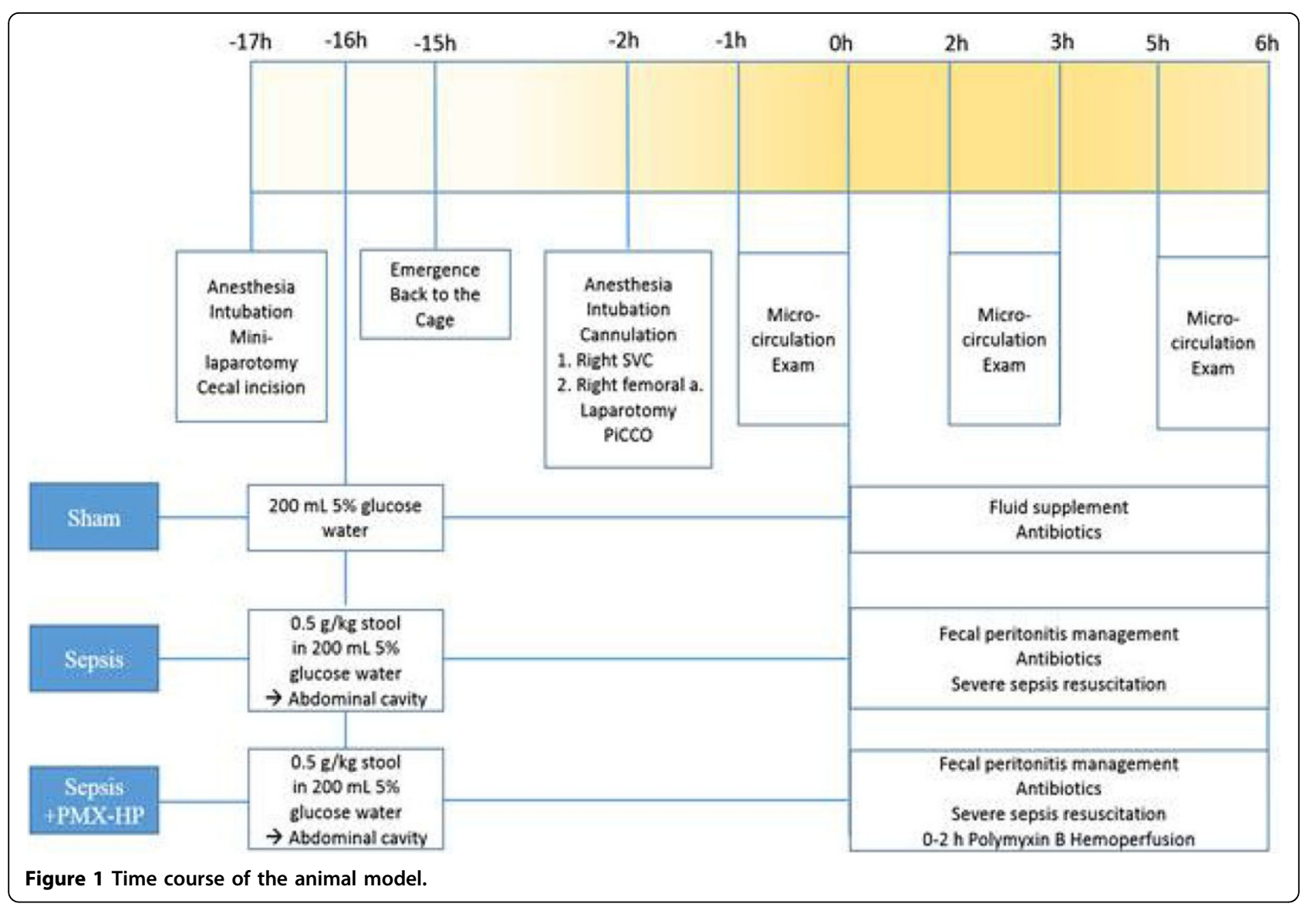

Table 1 Hemodynamic parameters.

\begin{tabular}{llll}
\hline & Sham & Sepsis & Sepsis + PMX-HP \\
\hline N & 4 & 4 & 4 \\
\hline HR_Oh (bpm) & $132(14)$ & $160(22)$ & $174(28)$ \\
\hline HR_6h (bpm) & $127(49)$ & $188(3)$ & $169(13)$ \\
\hline MAP_0h $(\mathrm{mm} \mathrm{Hg})$ & $90(12)$ & $94(20)$ & $80(26)$ \\
\hline MAP_6h $(\mathrm{mm} \mathrm{Hg})$ & $74(8)$ & $77(18)$ & $75(5)$ \\
\hline Cl_Oh $(\mathrm{L} / \mathrm{min} / \mathrm{m} 2)$ & $3.5(0.7)$ & $3.4(1.3)$ & $3.4(0.4)$ \\
\hline Cl_Oh $(\mathrm{L} / \mathrm{min} / \mathrm{m} 2)$ & $3.3(0.6)$ & $3.4(0.3)$ & $3.1(0.7)$ \\
\hline EVLWI_Oh $(\mathrm{mL} / \mathrm{kg})$ & $11.8(2.6)$ & $14.4(2.7)$ & $12.3(1.9)$ \\
\hline EVLWI_6h $(\mathrm{mL} / \mathrm{kg})$ & $13.5(2.4)$ & $17.4(4.7)$ & $14.5(4.6)$ \\
\hline
\end{tabular}



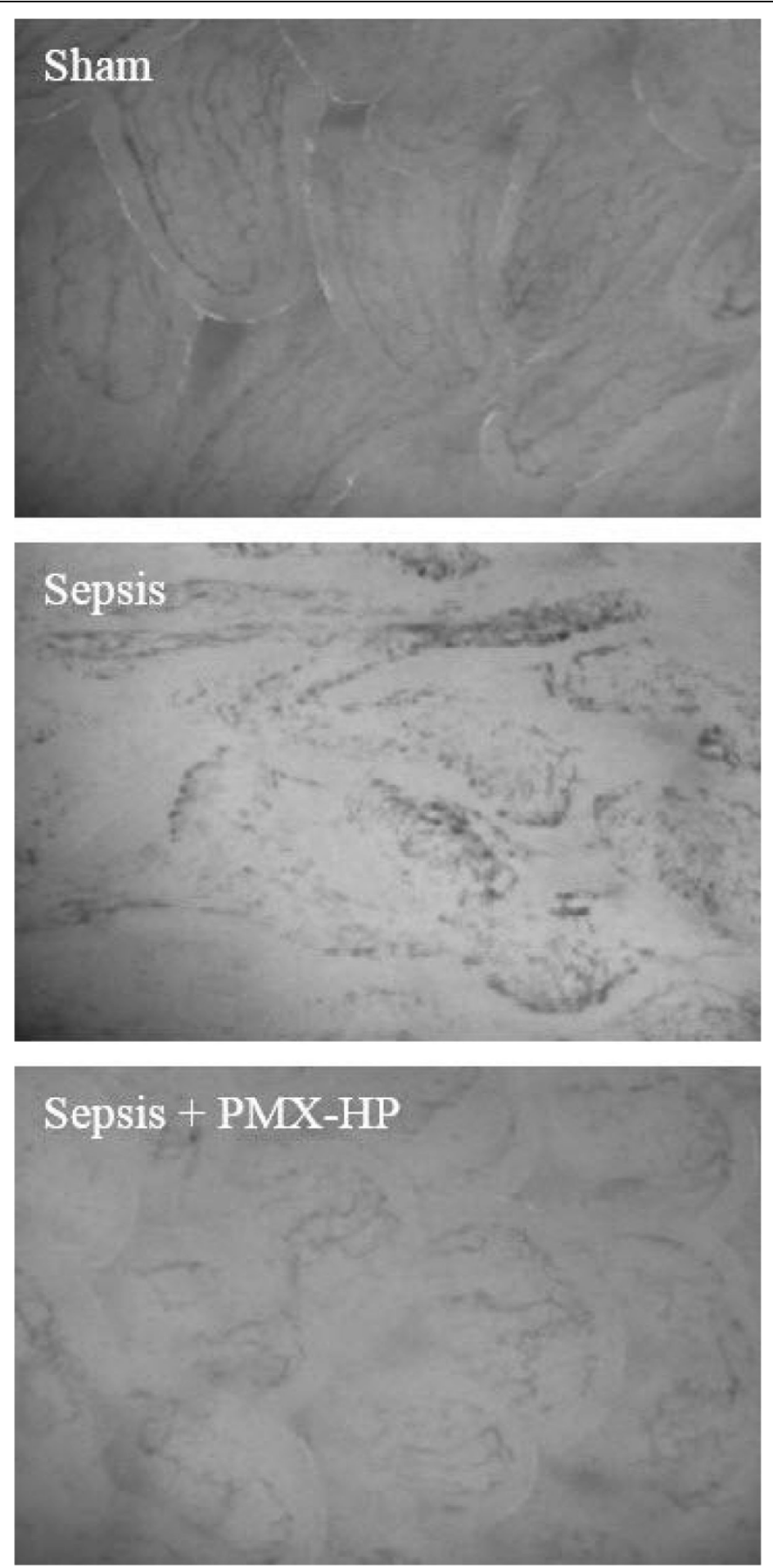

Figure 2 Microcirculation of terminal ileal mucosa (6h). 
Table 2 Microcirculation comparison.

\begin{tabular}{lllll}
\hline & & Sham & Sepsis & Sepsis + PMX-HP \\
\hline Intestinal mucosa & PSVD_Oh $(\mathrm{mm} / \mathrm{mm} 2)$ & $30.0(2.4)$ & $25.2(3.9)$ & $23.5(5.0)$ \\
\hline & PSVD_6h $(\mathrm{mm} / \mathrm{mm} 2)$ & $31.2(2.2)$ & $16.3(11.7)$ & $25.7(5.1)$ \\
\hline StO2_0h (\%) & $54(7)$ & $41(18)$ & $41(22)$ \\
\hline Kidney & StO2_6h (\%) & $66(2)$ & $42(16)$ & $48(6)$ \\
\hline & PSVD_0h $(\mathrm{mm} / \mathrm{mm} 2)$ & $35.1(3.0)$ & $26.9(12.1)$ & $24.0(7.5)$ \\
\hline & PSVD_6h (mm/mm2) & $37.3(2.0)$ & $22.8(17.6)$ & $24.2(4.3)$ \\
\hline & StO2_0h (\%) & $69(12)$ & $58(8)$ & $63(11)$ \\
\hline
\end{tabular}
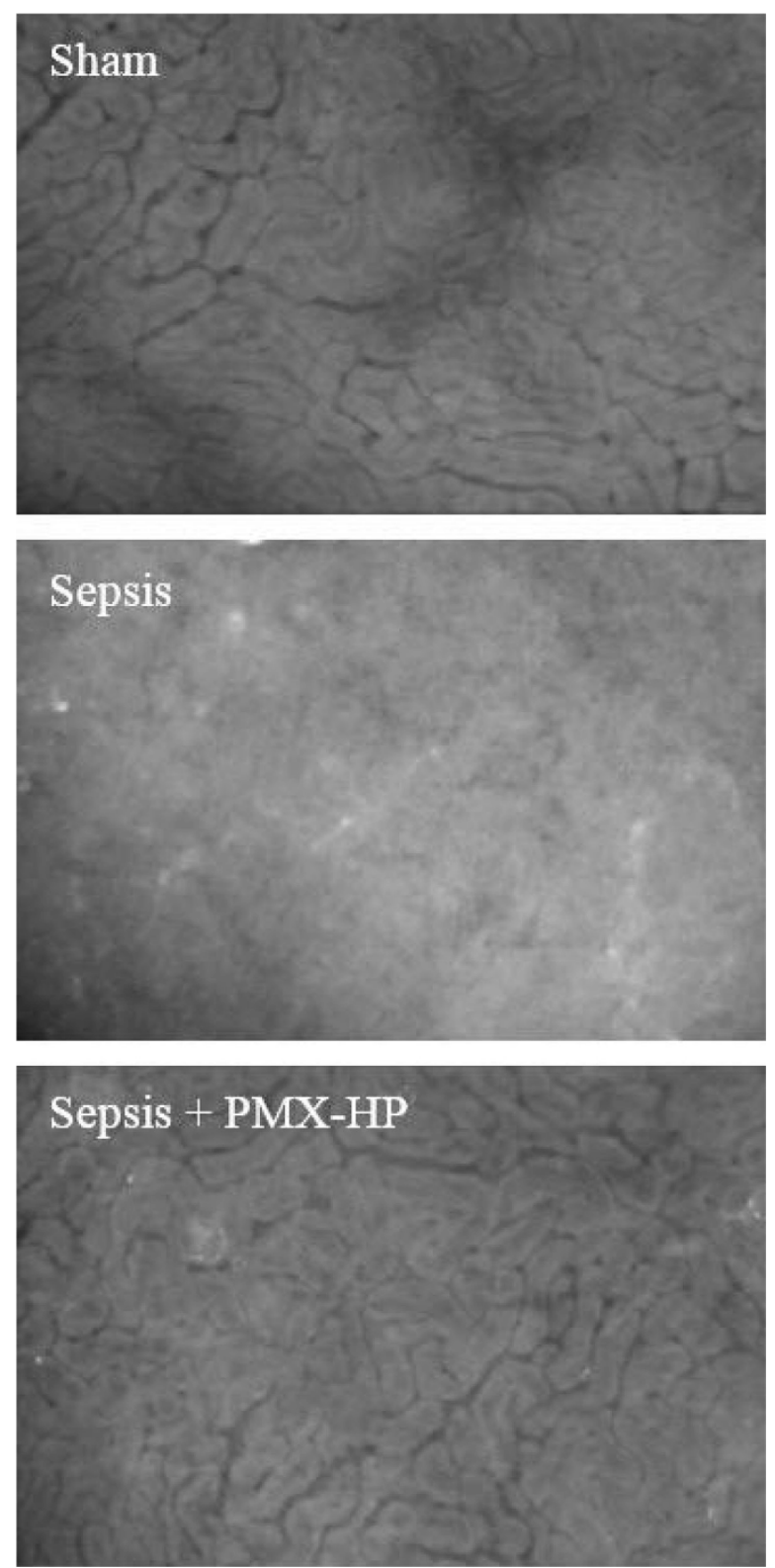

Figure 3 Microcirculation of kidney surface (6h). 
Table 3 Vasopressor, urine output, and laboratory results.

\begin{tabular}{llll}
\hline & Sham & Sepsis & Sepsis + PMX-HP \\
\hline Norepinephrine_6h $(\mathrm{mcg} / \mathrm{kg} / \mathrm{min})$ & $0.09(0.16)$ & $0.62(0.56)$ & $0.33(0.39)$ \\
\hline Fluid therapy 0-6h $(\mathrm{mL})$ & $2212(754)$ & $2912(999)$ & $3262(430)$ \\
\hline Urine output 0-6h $(\mathrm{mL})$ & $191(30)$ & $131(69)$ & $256(71)$ \\
\hline Creatinine_0h $(\mathrm{mg} / \mathrm{dL})$ & $1.3(0.2)$ & $1.6(0.9)$ & $1.5(0.3)$ \\
\hline Creatinine_6h $(\mathrm{mg} / \mathrm{dL})$ & $1.3(0.2)$ & $2.0(1.3)$ & $1.5(0.6)$ \\
\hline ALT_0h $(\mathrm{U} / \mathrm{L})$ & $24(5)$ & $33(3)$ & $27(6)$ \\
\hline ALT_6h $(\mathrm{U} / \mathrm{L})$ & $20(5)$ & $32(11)$ & $22(3)$ \\
\hline Lactate_Oh $(\mathrm{mmol} / \mathrm{L})$ & $1.2(0.5)$ & $3.9(2.5)$ & $3.9(1.9)$ \\
\hline Lactate_6h $(\mathrm{mmol} / \mathrm{L})$ & $1.6(0.6)$ & $4.2(1.9)$ & $3.8(3.1)$ \\
\hline
\end{tabular}

\section{Authors' details}

${ }^{1}$ National Taiwan University Hospital, Department of Anesthesiology, Taipei,

Taiwan, Province of China. ${ }^{2}$ Far Eastern Memorial Hospital, Department of

Anesthesiology, New Taipei, Taiwan, Province of China.

Published: 1 October 2015

\section{References}

1. De Backer, Creteur J, Preiser JC, Dubois MJ, Vincent JL: Microvascular blood flow is altered in patients with sepsis. Am J Respir Crit Care Med 2002, 166:98-104.

2. Cruz DN, Perazella MA, Bellomo R, de Cal M, Polanco N, Corradi V, et al: Crit Care 2007, 11(2):R47

3. Iba T, Okamoto K, Kawasaki S, Narakai E, Miyasho T: J Surg Res 2010, 171(2):755-761.

Cite this article as: Yeh et al:: The effect of endotoxin adsorber haemoperfusion on microcirculation in septic pigs. Intensive Care Medicine Experimental 2015 3(Suppl 1):A420.

\section{Submit your manuscript to a SpringerOpen ${ }^{\circ}$ journal and benefit from:}

- Convenient online submission

- Rigorous peer review

- Immediate publication on acceptance

- Open access: articles freely available online

- High visibility within the field

- Retaining the copyright to your article

Submit your next manuscript at $>$ springeropen.com 